\title{
Estradiol Is a Critical Mediator of Macrophage-Nerve Cross Talk in Peritoneal Endometriosis
}

\author{
Erin Greaves, ${ }^{*}$ Julia Temp ${ }^{\dagger \dagger}$ Arantza Esnal-Zufiurre, ${ }^{*}$ Sylvia Mechsner, ${ }^{\dagger}$ Andrew W. Horne, ${ }^{*}$ and Philippa T.K. Saunders*
}

From the Medical Research Council Centre for Reproductive Health,* The University of Edinburgh, Queen's Medical Research Institute, Edinburgh, United Kingdom; Endometriosis Centre Charité, ${ }^{\dagger}$ Department of Gynecology, Charité, Campus Benjamin Franklin, Berlin, Germany; and the Department of Biology, Chemistry, and Pharmacy, ${ }^{\ddagger}$ Free University of Berlin, Berlin, Germany

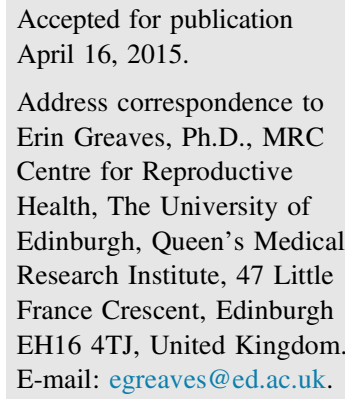

Endometriosis occurs in approximately $10 \%$ of women and is associated with persistent pelvic pain. It is defined by the presence of endometrial tissue (lesions) outside the uterus, most commonly on the peritoneum. Peripheral neuroinflammation, a process characterized by the infiltration of nerve fibers and macrophages into lesions, plays a pivotal role in endometriosis-associated pain. Our objective was to determine the role of estradiol (E2) in regulating the interaction between macrophages and nerves in peritoneal endometriosis. By using human tissues and a mouse model of endometriosis, we demonstrate that macrophages in lesions recovered from women and mice are immunopositive for estrogen receptor $\beta$, with up to $20 \%$ being estrogen receptor $\alpha$ positive. In mice, treatment with E2 increased the number of macrophages in lesions as well as concentrations of mRNAs encoded by $C s f 1, N t 3$, and the tyrosine kinase neurotrophin receptor, TrkB. By using in vitro models, we determined that the treatment of rat dorsal root ganglia neurons with E2 increased mRNA concentrations of the chemokine C-C motif ligand 2 that stimulated migration of colony-stimulating factor 1-differentiated macrophages. Conversely, incubation of colony-stimulating factor 1 macrophages with E2 increased concentrations of brainderived neurotrophic factor and neurotrophin 3, which stimulated neurite outgrowth from ganglia explants. In summary, we demonstrate a key role for E2 in stimulating macrophage-nerve interactions, providing novel evidence that endometriosis is an estrogen-dependent neuroinflammatory disorder. (Am J Pathol 2015, 185: 2286-2297; http://dx.doi.org/10.1016/j.ajpath.2015.04.012)
Endometriosis affects $10 \%$ of reproductive age women and is associated with persistent pelvic pain. ${ }^{1}$ It is defined by the presence of endometrial-like tissue (lesions) found outside the uterus, most commonly on the peritoneum. The mechanisms underlying endometriosis-associated pain are poorly understood, but it has been postulated that estrogen-dependent neuroinflammation may be involved. ${ }^{2}$ Notably, the presence of endometrial tissue fragments on the peritoneum elicits an immune response, including recruitment of macrophages, ${ }^{3}$ blood vessels, and nerve fibers into the resultant lesions. ${ }^{4,5}$ Within the lesions, $\mathrm{CD}^{+} 8^{+}$macrophages have been detected in close association with nerve fibers. ${ }^{6}$

Studies investigating macrophage activation and recruitment have revealed that endometriosis-associated macrophages exhibit a phenotype consistent with the alternative end of the macrophage activation spectrum. ${ }^{7,8}$ In a mouse model of endometriosis that included cell transfer of polarized macrophages, Bacci et $\mathrm{al}^{7}$ reported that mice injected with proinflammatory macrophages [macrophage (interferon $\gamma$ )] developed microscopic lesions, but those injected with alternatively activated macrophages [macrophage (IL-4)] developed larger lesions with a well-developed vasculature. Our studies in a mouse model of endometriosis have revealed that macrophages resident in peritoneal lesions can originate from both the peritoneum and the endometrium.

Supported by a Society for Endocrinology Early Career grant (E.G.), a Medical Research Council Program grant G1100356/1 (P.T.K.S.), a Wellbeing of Women grant R42533 (A.W.H.), and a Boehringer Ingelheim Fonds travel grant (J.T.).

Disclosures: None declared. 
Table 1 Primer Sequences

\begin{tabular}{|c|c|c|c|}
\hline Gene & Species & Forward primer & Reverse primer \\
\hline Csf1 & Rat & $5^{\prime}-$ CAAGGACTATAAGGAACAGAACGAG- $3^{\prime}$ & $5^{\prime}$-GAAATTCTTGATTTTCTCCAGCA-3' \\
\hline Ccl2 & Rat & 5'-AGCATCCACGTGCTGTCTC-3' & 5'-GATCATCTTGCCAGTGAATGAG-3' \\
\hline Csf1 & Mouse & 5'-GGGGGCCTCCTGTTCTAC-3' & 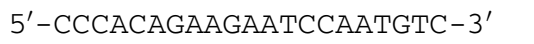 \\
\hline Ccl2 & Mouse & 5'-CATCCACGTGTTGGCTCA-3' & $5^{\prime}$-GATCATCTTGCTGGTGAATGAGT-3' \\
\hline $\mathrm{Ccl3}$ & Mouse & 5'-TGCCCTTGCTGTTCTTCTCT-3' & $5^{\prime}$-GTGGAATCTTCCGGCTGTAG-3' \\
\hline Nt3 & Mouse & 5'-GGTGGTACCCTCTCCTCACTC-3' & $5^{\prime}$-GAAGAGCCCCTGTCATTCTG-3' \\
\hline Ntrk2 & Mouse & 5'-TTCTGCCTGCTGGTGATGT-3' & $5^{\prime}-$ TCCAGTGGGATCTTATGAAACA-3' \\
\hline
\end{tabular}

Sensory C, sensory A $\delta$, cholinergic, and adrenergic nerve fibers have been identified within lesions, ${ }^{10,11}$ with greater nerve fiber density in areas that exhibit high macrophage density. ${ }^{6}$ Studies in zebrafish have shown that macrophages will migrate toward damaged peripheral nerves, ${ }^{12}$ consistent with a role for neuron-derived factors in immune-nerve cross talk.

Endometriosis lesions have an estrogen-rich microenvironment associated with enhanced expression of biosynthetic enzymes, including aromatase. ${ }^{13}$ It is well established that estrogen action can be mediated by estrogen receptors $\alpha(E R \alpha)$ and $\beta$ (ER $\beta)$, both widely expressed are the human endometrium. ${ }^{14}$ Notably, a proportion of the soma of afferent nerve fibers innervating the uterus and peritoneum is reported to express one or both ERs. ${ }^{15}$ Although some studies have analyzed the expression of ERs in macrophages isolated from the peritoneal fluid of women with endometriosis, ${ }^{16,17}$ expression of ERs in lesion-resident macrophages has not yet been determined.

Our objective was to determine whether estradiol (E2) plays a role in the regulation of macrophage-nerve cross talk in endometriosis by exploring both the expression of ERs in human tissue samples and the impact of E2 on nerves and macrophages using in vitro and in vivo models.

\section{Materials and Methods}

\section{Human Tissues}

Eutopic endometrium $(n=5)$ and peritoneal endometriosis lesions $(n=10)$ from patients with endometriosis were collected during laparoscopy (means $\pm \mathrm{SD}$ age, $35.1 \pm 6.08$ years; range, 26 to 45 years). Fixed sections of endometriosis lesions were evaluated after staining with hematoxylin and eosin, and only those that contained both glandular and stromal compartments were used for this study. Dating of eutopic endometrial histological features ${ }^{18}$ and serum hormone measurements were used to confirm menstrual cycle phase. Endometriosis stage was provided during surgery using the revised American Society of Reproductive Medicine classification (I, 60\%; II, 20\%; III, 20\%). Endometrium $(n=5)$ and peritoneal $(n=8)$ biopsy specimens from women without evidence of clinical endometriosis were also collected during laparoscopy. All patients had regular cycles and had not taken hormones at least 3 months before surgery. The study was approved by the Lothian Research Ethics Committee (number 11/AL/0376) and the Ethics Committee of Charité-University Medicine Berlin (EA4/ 023/05). All patients provided written, informed consent. Samples were fixed in $4 \%$ neutral-buffered formalin or stored in RNAlater (Applied Biosystems, Warrington, UK).

\section{Mouse Model of Endometriosis}

Endometriosis was induced using wild-type and transgenic colony stimulating factor 1 receptor-enhanced green fluorescent protein (Csf1r-EGFP) mice (MacGreen; founder stocks were a gift from Bernadette Dutia and Prof. David Hume, The Roslin Institute, The University of Edinburgh, UK) ${ }^{19}$ on a C57BL/6 background using a previously validated model of endometriosis, as described. ${ }^{9}$ In brief, donor endometrial tissue was recovered during induced menses ${ }^{20}$ and injected into the peritoneal cavity of recipient mice. Lesions and peritoneum were collected from endometriosis mice $(n=8) 21$ days after inoculation of the peritoneum. In an additional group of mice, on day 21, the E2 s.c. pellet was either removed (no hormone control; $n=5$ ) or retained (E2 treatment; $n=8$, mice randomly assigned to groups). After a further 7 days (day 28 of

Table 2 Antibodies Used in Immunofluorescence

\begin{tabular}{llll}
\hline Antibody (manufacturer) & Raised in animal & Tissue & Dilution \\
\hline ERß1 (no. MCA1974S; Serotec, Kidlington, UK) & Mouse & Human & $1: 500$ \\
ER $\beta$ (no. SC-8974; Santa Cruz Biotechnology, Dallas, TX) & Rabbit & Mouse & $1: 500$ \\
ER $\alpha$ (Vector Laboratories, Peterborough, UK) & Mouse & Human and mouse & $1: 500$ \\
PGP9.5 (Dako, Cambridge, UK) & Rabbit & Human and mouse & $1: 1000$ and 1:3500 \\
CD68 (clone KPI; Dako) & Mouse & Human & $1: 1200$ \\
GFP (no. A11122; Life Technologies) & Rabbit & Mouse & $1: 1500$ \\
\hline
\end{tabular}

ER, estrogen receptor; GFP, green fluorescent protein; PGP, protein gene product. 

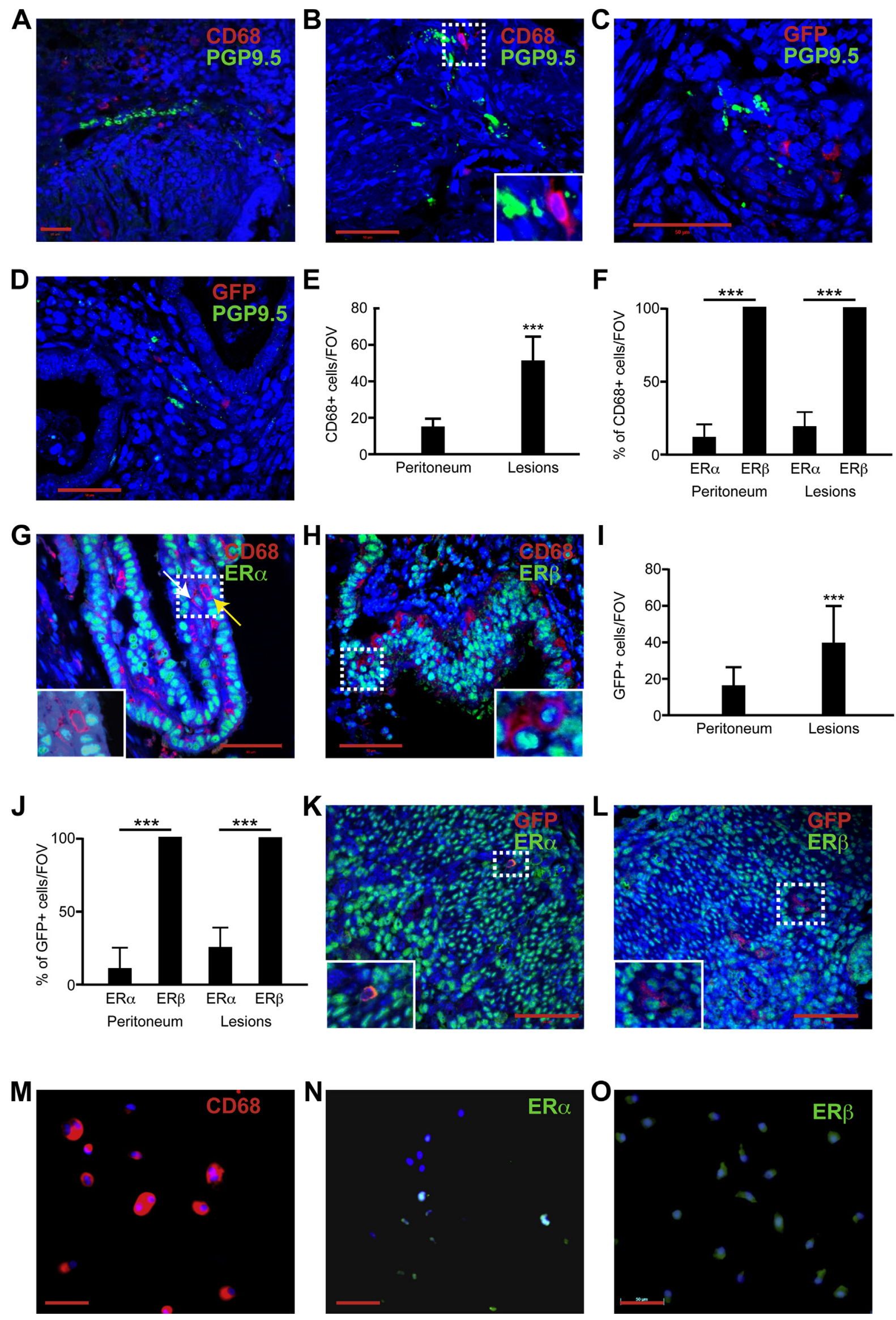
the protocol), mice were culled, lesions and peritoneum were removed and either stored in RNAlater or fixed in neutralbuffered formalin, and processed to confirm the presence of glands and stroma. Control tissues (uterus and peritoneum) were recovered from naïve control mice $(n=6)$.

\section{Cell Culture and E2 Treatments}

\section{DRG Isolation}

Rat dorsal root ganglia (DRG) were isolated as previously described. ${ }^{21}$ Dissociated DRGs were used for RNA extraction and quantitative RT-PCR (RT-qPCR). At least 24 hours before experiments, the medium was changed to phenol red free media, and fetal calf serum was stripped with activated charcoal, then added to the media at a concentration of $1 \%$. Cells were stimulated with vehicle control [dimethyl sulfoxide (DMSO)], E2 at a final concentration of $10^{-8} \mathrm{~mol} / \mathrm{L}$ (Sigma, Poole, UK), alone or in combination with the anti-estrogen fulvestrant (ICI 182780; final concentration, $10^{-7} \mathrm{~mol} / \mathrm{L}$; Tocris, Birmingham, UK). E2 and ICI were dissolved in DMSO to yield stock solutions of $10^{-2} \mathrm{~mol} / \mathrm{L}$, and all cells were exposed to a final DMSO concentration of $1: 1 \times 10^{4}$ dilution. DRG conditioned media (CM) were collected, centrifuged, and stored at $-80^{\circ} \mathrm{C}$ and used for the macrophage migration assay. All experiments were performed in triplicate.

\section{Human Peripheral Blood Monocyte Isolation and Macrophage Differentiation}

Human venous blood was collected from healthy female volunteers $(n=5)$ with informed consent (Lothian Research Ethics Committee number 08/S1103/38). To isolate mononuclear leukocytes, blood was centrifuged $(350 \times g, 20$ minutes $)$ and platelet-rich plasma was aspirated. Erythrocytes were sedimented with $0.6 \%$ (w/v) dextran, followed by separation of leukocytes using a Percoll (GE Healthcare, Hatfield, UK) gradient and centrifugation at $720 \times g$ for 20 minutes. Mononuclear leukocytes were aspirated and monocytes were isolated by negative selection using a monocyte isolation kit II (Miltenyi Biotech, Surrey, UK). Adherent monocytes were cultured in the presence of $4 \mathrm{ng} / \mathrm{mL}$ colony-stimulating factor 1 (CSF-1) to generate monocyte-derived macrophages, hereby referred to as $\mathrm{M}(\mathrm{CSF}-1)$ in accordance with the recently published macrophage nomenclature guidelines. ${ }^{22}$ They were cultured for 4 days in Iscove's Dulbecco's modified Eagle's medium (Life Technologies, Paisley, UK) containing 10\% autologous serum and prepared by recalcification of platelet-rich plasma (12-well plates, $37^{\circ} \mathrm{C}$ in $\left.5 \% \mathrm{CO}_{2}\right)$. $\mathrm{M}(\mathrm{CSF}-1)$ were exposed to DMSO [M(CSF-1 + DMSO], $10^{-8} \mathrm{~mol} / \mathrm{L}$ E2 [M(CSF-1) + E2], or $10^{-8} \mathrm{~mol} / \mathrm{L} \mathrm{E} 2 \mathrm{plus} 10^{-7} \mathrm{~mol} / \mathrm{L} \mathrm{ICI}[\mathrm{M}(\mathrm{CSF}-1)+\mathrm{E} 2+\mathrm{ICI}]$ for 24 hours at $37^{\circ} \mathrm{C}$ using $5 \% \mathrm{CO}_{2}$ on day 5 . Macrophage $\mathrm{CM}$ were collected, centrifuged, and stored at $-80^{\circ} \mathrm{C}$ until further use for the neurite outgrowth assays. All experiments were performed in triplicate.

\section{RNA Extraction and cDNA Synthesis}

RNA was extracted from DRGs and macrophages using the RNAeasy mini kit (Qiagen, Sussex, UK), and concentration and purity were analyzed using a Nanodrop (LabTech International, Sussex, UK). cDNA was synthesized using SuperScript VILO (Invitrogen, Paisley, UK) with a starting template of $100 \mathrm{ng} / \mu \mathrm{L}$.

\section{Quantitative Real-Time PCR}

Real-time PCR was performed using the Roche Universal ProbeLibrary (Roche Applied Science, West Sussex, UK) and Express qPCR Supermix (Invitrogen) in a 7900 Fast Real-Time PCR, with $18 \mathrm{~S}$ as the endogenous control. Primer sequences (Eurofins MWG Operon, Ebersberg, Germany) are listed in Table 1. Expression of target genes was related to expression of $18 \mathrm{~S}$ ribosomal RNA and to an internal control sample using the $2^{-\Delta \Delta \mathrm{Ct}}$ method.

\footnotetext{
Figure 1 Macrophages are found in close association with nerve fibers in endometriosis lesions and express estrogen receptors. A and B: Macrophages are found in close proximity to small-diameter nerve fibers in human peritoneal lesion biopsy specimens. Dual immunofluorescence was performed using the macrophage marker CD68 (red) and the pan neuronal marker protein gene product 9.5 (PGP9.5; green). Nuclei stained with DAPI (blue). Inset in B is an enlarged image of boxed area. $\mathbf{C}$ and $\mathbf{D}$ : Macrophages are also found near small-diameter nerve fibers in lesions recovered from a mouse model of endometriosis. To aid in the localization of macrophages, we used the MacGreen mouse [a transgenic mouse with enhanced green fluorescent protein (GFP)-labeled macrophages] for our mouse model of endometriosis. Dual immunofluorescence was performed using an anti-GFP antibody (red) PGP9.5 (green) on lesions recovered from mice. Nuclei stained with DAPI (blue). E: Significantly more $\mathrm{CD}_{68}{ }^{+}$macrophages were detected in peritoneal endometriosis lesions compared with the healthy peritoneum. $\mathrm{CD} 8^{+}$cells were counted in four randomly selected fields of view (FOVs) associated with glandular and stromal tissue in lesions, the mean was recorded for each patient sample, and statistical analysis was performed using a Student's unpaired $t$-test. $\mathbf{F}-\mathbf{H}$ : 0 f macrophages in peritoneal lesions, $20 \%$ are immunopositive for estrogen receptor (ER) $\alpha$, and $100 \%$ are immunopositive for ER $\beta$. F: $C D 68^{+}$ER $\alpha^{+}$cells were counted in each FOV and expressed as a proportion of CD68 ${ }^{+}$cells; statistical analysis was performed using a one-way analysis of variance and Newman Keuls post test. G: ER $\alpha$ immunolocalization in endometriosis lesions (CD68, red; $E R \alpha$, green). Inset: Enlarged area of boxed area with an $E R \alpha^{+}$macrophage (white arrow) adjacent to an $E R \alpha^{-}$macrophage (yellow arrow). H: Macrophages in peritoneal lesions are immunopositive for ER $\beta$ (green); inset is enlarged image of boxed area. I: Significantly more $\mathrm{GFP}^{+}$macrophages were detected in peritoneal endometriosis lesions compared with the healthy peritoneum. GFP ${ }^{+}$cells were counted in four randomly selected FOVs associated with glandular and stromal tissue in lesions, the mean was recorded for each sample, and statistical analysis was performed using a Student's unpaired $t$-test. J-L: 0f macrophages in mouse peritoneal lesions, 25\% are immunopositive for ER $\alpha$, and 100\% are immunopositive for ER $\beta$. J: GFP $\mathrm{GR}^{+}$cells were counted in each FOV and expressed as a proportion of GFP cells; statistical analysis was performed using a one-way analysis of variance and Newman Keuls post test. K: ER $\alpha$ immunolocalization in endometriosis lesions (GFP, red; ER $\alpha$, green). L: Macrophages in mouse peritoneal lesions are immunopositive for ER $\beta$ (green). Insets in $\mathbf{K}$ and $\mathbf{L}$ are enlarged images of boxed area. $\mathbf{M - 0}$ : Peripheral blood monocytes were isolated and differentiated into macrophages in the presence of CSF-1. M: Phenotype of cultured

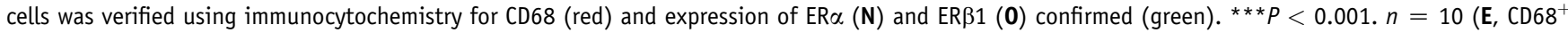
macrophages in peritoneal endometriosis lesions $) ; n=8\left(\mathrm{E}, \mathrm{CD}^{+} 8^{+}\right.$macrophages in healthy peritoneum $) ; n=8\left(\mathbf{I}, \mathrm{GFP}^{+}\right.$macrophages in peritoneal endometriosis lesions); $n=6$ (I, GFP ${ }^{+}$macrophages in healthy peritoneum). Scale bars: $20 \mu \mathrm{m}(\mathbf{A}) ; 50 \mu \mathrm{m}(\mathbf{B}-\mathbf{D}, \mathbf{H}$, and $\mathbf{L})$.
} 


\section{Functional Assays}

\section{Neurite Outgrowth Assay}

Single whole DRG explants from embryonic day 15.5 rat embryos were incubated with Dulbecco's modified Eagle's medium plus $0.1 \mathrm{ng} / \mathrm{mL}$ nerve growth factor (positive control), Iscove's Dulbecco's modified Eagle's medium plus autologous serum (negative control), or CM from macrophages treated for 24 hours with DMSO, E2, or E2 + ICI ( $n=5$ female volunteers). They were incubated for 24 and 48 hours at $37^{\circ} \mathrm{C}$ with $5 \% \mathrm{CO}_{2}$ in poly-D-lysine and Matrigel (BD Biosciences, Oxford, UK) coated 12-well plates. Neurite outgrowth was analyzed as previously described. $^{21}$ Neutralization experiments were performed using $0.4 \mu \mathrm{g} / \mathrm{mL}$ anti-brain-derived neurotrophic factor (BDNF) and $0.2 \mu \mathrm{g} / \mathrm{mL}$ anti-neurotrophin 3 (NT-3; R\&D Systems, Oxford, UK). CM was preincubated with neutralizing antibodies for 1 hour before experiments were performed. The treatments were performed in duplicate for each of the five patients, and each duplicate was used to incubate three DRGs.

\section{Macrophage Migration Assay}

The macrophage migration assay was performed using $\mu$ Slide V1.04 migration slides (Ibidi, Munich, Germany). CM $(80 \mu \mathrm{L})$ from DRG exposed to DMSO, E2, or E2 + ICI was placed in one chamber, macrophages $\left(5 \times 10^{4}\right.$ cells $)$ were placed in the other chamber, and slides were incubated for 16 hours, then evaluated using an Axiovert microscope (Carl Zeiss, Oberkochen, Germany). A migration score was allocated to each slide on the basis of the distance migrated and the percentage of macrophages mobilized toward the chamber containing the DRG media. Neutralization experiments were performed using $0.5 \mu \mathrm{g} / \mathrm{mL}$ anti-chemokine (C-C motif) ligand 2 (CCL-2) antibody (BioLegend, San Diego, CA) and an anti-CCL-3 antibody $(0.45 \mu \mathrm{g} / \mathrm{mL}$; R\&D Systems). CM was preincubated with neutralizing antibodies for 1 hour before experiments were performed. DRG treatments were performed in triplicate in four separate experiments and used in migration experiments from four macrophage preparations (four female volunteers).

\section{Immunodetection}

\section{Dual Immunofluorescence}

Dual immunofluorescence was performed as previously described..$^{21}$ In brief, sections were antigen retrieved, blocked for endogenous peroxidase and non-specific epitopes, and incubated with primary antibody at $4{ }^{\circ} \mathrm{C}$ overnight (Table 2). Antibody detection was performed using a secondary $\mathrm{F}(\mathrm{ab})$ polyclonal antibody to IgG (horseradish peroxidase) and a tyramide signal amplification (TSA) system kit labeled with Cy3 (red) or fluorescein (green; 1:50 dilution; Perkin Elmer Inc., Waltham, MA). For detection of the second antigen, sections were microwaved in boiling citrate buffer, and the second primary antibody was applied overnight at $4{ }^{\circ} \mathrm{C}$, and detected as above. The sections were counterstained with DAPI, mounted in Permafluor (Thermo Fisher Scientific, Loughborough, UK), and imaged using a LSM710 confocal microscope and AxioCam camera (Carl Zeiss). Human or mouse uterus was used as a positive control tissue, and negative controls had omission of the primary antibody. Macrophage number in lesion and peritoneal sections was quantified by randomly capturing four (human) or three (mouse) fields of view associated with glandular and stromal tissue in endometriosis lesions. A mean was generated and plotted for each biological sample. ${ }^{21}$

\section{Immunofluorescence on Cultured Cells}

Cultured DRGs were stained using a NF $\mathrm{H}$ chicken antineurofilament $\mathrm{H}$ antibody (1:1000; BioLegend, San Diego, CA) to visualize neurite projections. Cultured macrophages were fixed for 20 minutes using ice-cold methanol, permeabilized using Triton X-100 (Sigma), and blocked with Avidin/Biotin (Vector, Peterborough, UK) and species-specific blocking buffer for non-specific epitopes. Macrophages were incubated with primary antibody (CD68, ER $\alpha$, or ER $\beta$ ) overnight at $4^{\circ} \mathrm{C}$. Antibody binding was detected using a biotinylated secondary antibody, followed by streptavidin Alexa Fluor 555 (Life Technologies), and counterstained with DAPI. Images were captured using an Axiovert microscope (Carl Zeiss), Axiovision camera, and software.

\section{Statistical Analysis}

The data were expressed as means \pm SEM and were analyzed using a one-way analysis of variance and a Newman Keuls multiple-comparison test or a $t$-test for two-group comparisons. Analysis of qPCR data was performed on transformed values. Analyses were performed using GraphPad Prism software version 6 (Prism, La Jolla, CA).

\section{Results} Macrophages and Nerve Fibers Are Found in Close
Association in Peritoneal Endometriosis Lesions

In peritoneal lesions from women with endometriosis, macrophages (immunopositive for CD68, red) were identified in close association with small-diameter nerve fibers, typical of afferent sensory innervation (Figure 1, A and B). Clustering of CD68 ${ }^{+}$ macrophages around nerve bundle structures was consistently observed in tissue close to glandular epithelium in peritoneal lesions (Supplemental Figure S1). In lesions recovered from transgenic Csf1r-EGFP(MacGreen) mice, $\mathrm{GFP}^{+}$macrophages were also detected close to nerve fibers (Figure 1, C and D).

\section{ER $\beta$ Is the Predominant ER Expressed by Lesion-Resident Macrophages}

Significantly more $\mathrm{CD} 68^{+}$macrophages were detected in sections of peritoneal endometriosis lesions compared with 
A

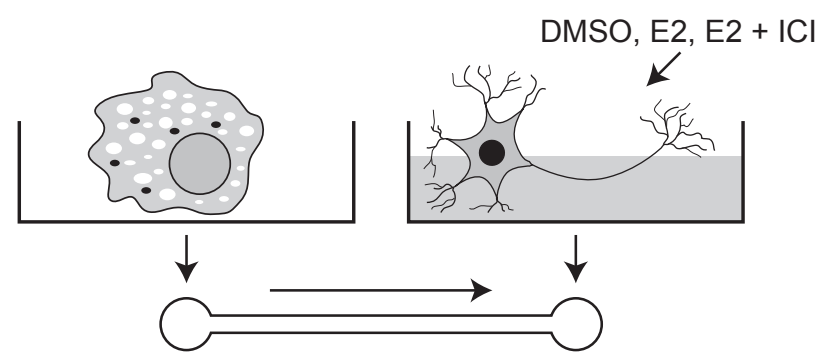

C

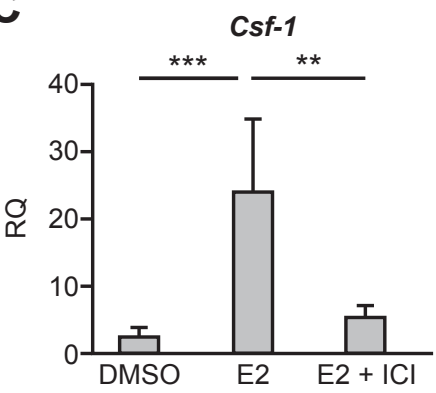

D

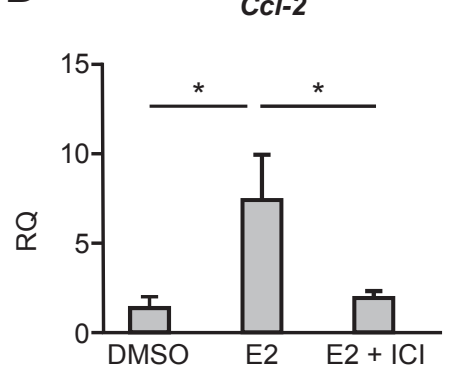

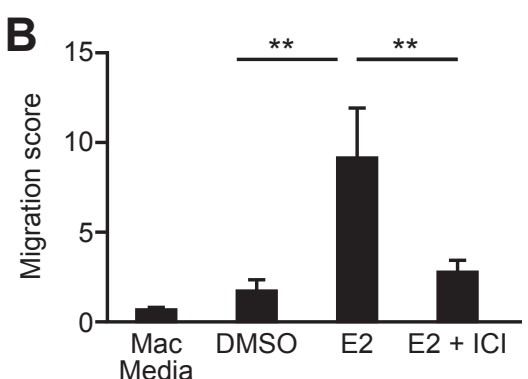

E

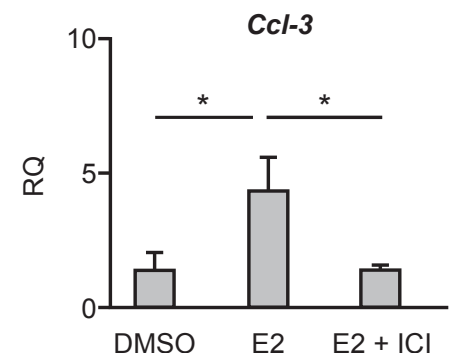

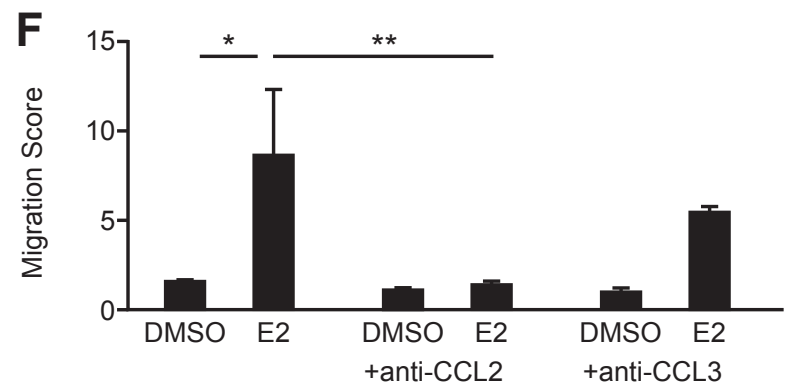

Figure 2 Nerve fibers recruit macrophages in an estradiol (E2)-dependent manner via C-C motif ligand (Ccl)-2. A: Dorsal root ganglia (DRG) were stimulated for 24 hours with vehicle control [dimethyl sulfoxide (DMSO)], $10^{-8} \mathrm{~mol} / \mathrm{L} \mathrm{E2}$, or $10^{-7} \mathrm{~mol} / \mathrm{L}$ E2 plus the anti-estrogen ICI 182780 . Conditioned media (CM) were retained for use in the macrophage migration assay; macrophages stimulated with CSF-1 [M(CSF-1)]; $5 \times 10^{-4}$ mol/L cells per well were placed in one chamber of the migration slide, and DRG CM in the other chamber. B: M(CSF-1) migrate furthest toward CM from DRG exposed to E2 $(P<0.01)$. Migration score was based on percentage cells mobilized and distance migrated. Macrophages; $n=4$ patients, embryonic rat DRGs; $n=4$ pregnant dams. C-E: E2 up-regulates mRNA concentrations of Csf-1 and chemokines in DRGs. The concentration of mRNAs encoding the macrophage growth factor Csf-1 and chemokines (Ccl-2 and $\mathrm{Ccl}-3$ ) was analyzed using quantitative PCR in DRG exposed to DMSO, E2, or E2 plus ICI for 24 hours: Csf-1 (C), Ccl-2/monocyte chemotactic protein 1 (D), and Ccl-3/macrophage inflammatory protein-1 $\alpha(\mathbf{E})$. F: The macrophage migration assay was performed as in $\mathbf{B}$, with the addition of $0.5 \mu \mathrm{g} / \mathrm{mL}$ anti-CCL-2 or $0.45 \mu \mathrm{g} / \mathrm{mL}$ anti-CCL-3 antibodies to CM from DRGs exposed to DMSO or E2. Anti-CCL-2 abolished E2-induced chemotactic properties of DRG CM, whereas anti-CCL-3 only attenuated E2-induced chemotactic properties of DRG CM. Statistical analysis was performed using a one-way analysis of variance and Newman Keuls post test. ${ }^{*} P<0.05,{ }^{*} P<0.01$, and ${ }^{* *} P<0.0001 . n=4$ (B, patients for macrophages and pregnant dams for embryonic rat DRGs); $n=5$ cultures (C-E). Mac media, unconditioned macrophage media (negative control); RQ, relative quantification.

sections of unaffected peritoneum $(P<0.001)$ (Figure $1 \mathrm{E})$. In women, $\mathrm{CD}^{+} 8^{+}$macrophages resident in the eutopic endometrium were immunonegative for $\mathrm{ER} \alpha$ (Supplemental Figure S2A) but immunopositive for ER $\beta$ (Supplemental Figure S2B), regardless of whether they had been diagnosed with endometriosis (Supplemental Figure S2, C and D). In peritoneal biopsy specimens from women without endometriosis, $\mathrm{ER} \alpha$ immunolocalized to approximately a tenth of $\mathrm{CD} 8^{+}$macrophages $(10.6 \% \pm 3.85 \%)$ (Figure $1 \mathrm{~F}$ and Supplemental Figure S2E), but all of the macrophages were ER $\beta$ positive (Supplemental Figure S2F). In peritoneal endometriosis, lesions approximately a fifth of the $\mathrm{CD}^{+} 8^{+}$ macrophages $(18.3 \% \pm 4.37 \%)$ were immunopositive for $\mathrm{ER} \alpha$ (Figure 1G) and, as in the normal peritoneum, they were all immunopositive for ER $\beta$ (Figure 1H). Results obtained in our mouse model of endometriosis mirrored those in women with significantly more $\mathrm{GFP}^{+}$macrophages in lesions $(P<0.05)$ compared with the peritoneum of naïve mice (Figure 1I). A tenth of mouse peritoneal macrophages $(10.14 \pm 6.41)$ and a quarter of lesion resident macrophages $(24.82 \pm 5.57)$ were immunopositive for $\mathrm{ER} \alpha$ (Figure $1, \mathrm{~J}$ and $\mathrm{K}$ ), with all $\mathrm{GFP}^{+}$cells being immunopositive for $\mathrm{ER} \beta$ (Figure 1L).

Human peripheral blood monocytes were isolated and differentiated into macrophages that are classified as being at the alternative end of the macrophage activation spectrum $^{22}$ by incubating them in the presence of CSF-1, hereafter referred to as $\mathrm{M}(\mathrm{CSF}-1)$. $\mathrm{M}(\mathrm{CSF}-1)$ incubated with $\mathrm{E} 2$ are referred to as 


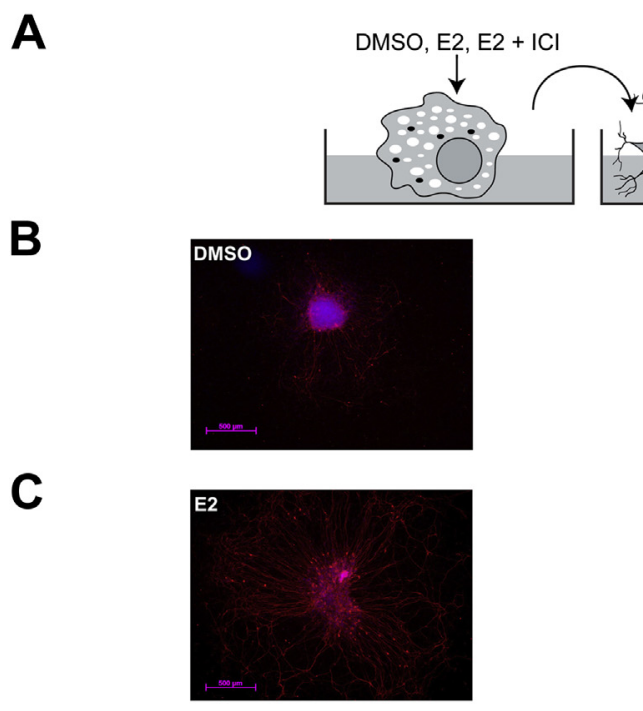

E
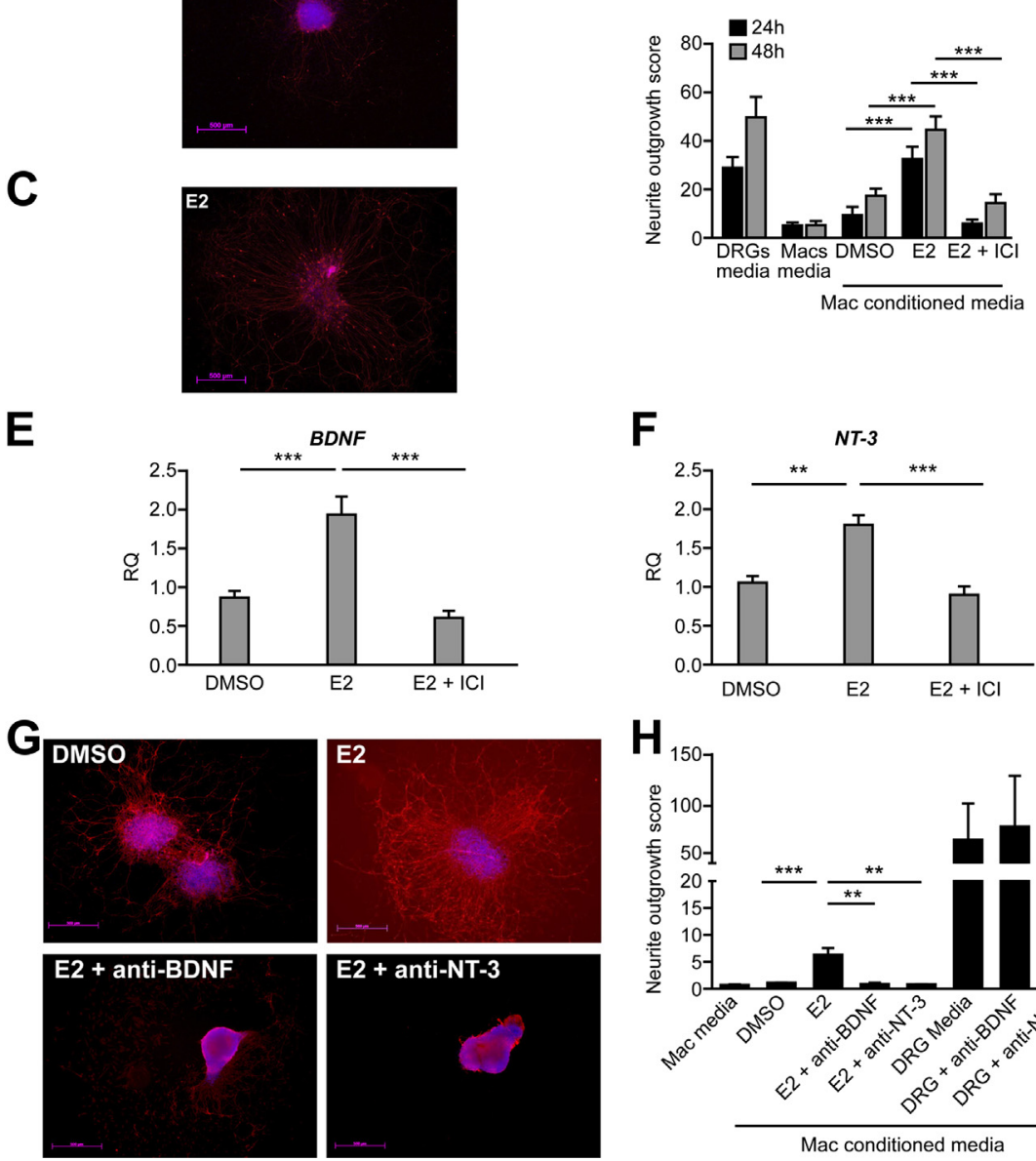

$\mathbf{F}$
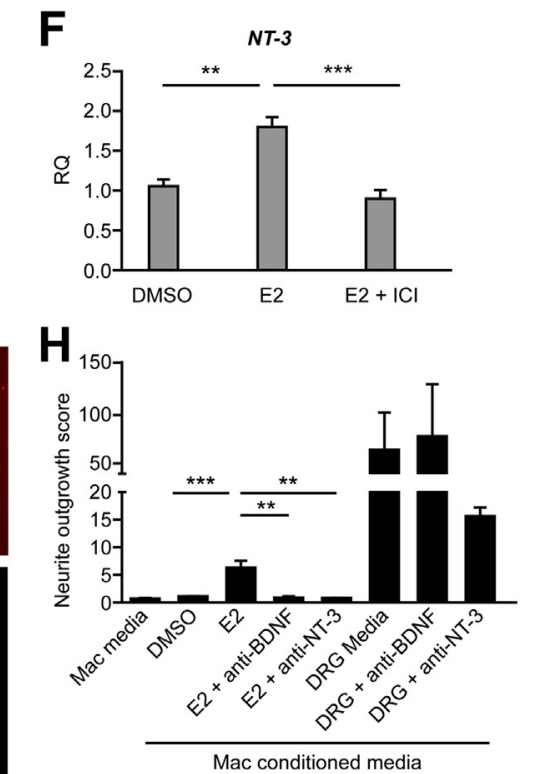

Figure 3 Macrophages stimulated with CSF1 and estradiol [M(CSF-1 + E2)] exhibit neurotrophic properties via brain-derived neurotrophic factor (BDNF) and neurotrophin (NT)-3. A: M(CSF1) were exposed to dimethyl sulfoxide (DMSO), E2, or E2 plus ICI 182780 , the conditioned media (CM) were retained and used to incubate single whole dorsal root ganglia (DRG) immediately dissected from embryonic rats. B-D: CM from $M(C S F-1+E 2)$ enhanced neurite outgrowth compared with CM from M(CSF-1 + DMSO). B and C: Immunocytochemistry performed on DRG using anti-neurofilament (red) and nuclei counterstained with DAPI (blue). B: DRG grown in CM from M(CSF-1 + DMS0). C: CM from M(CSF1 + E2). D: Neurite outgrowth was quantified; the score was based on the percentage coverage of DRG and average length of neurites. DRG media indicates nerve growth factor present, positive control; Mac media, negative control. E and F: The concentration of mRNAs encoding neurotrophins was analyzed using quantitative PCR in M(CSF-1) stimulated with DMSO, E2, or E2 plus ICI for 24 hours; BDNF (E) and NT-3 (F) are shown. $\mathbf{G}$ and $\mathbf{H}$ : The neurotrophic properties of M(CSF-1 + E2) are BDNF and NT-3 dependent. Whole single DRGs were cultured for 24 hours in CM from M(CSF-1 + DMSO) or M(CSF-1 + E2) for 24 hours, or CM from $M(C S F 1+E 2)$ in the presence of $0.4 \mu \mathrm{g} / \mathrm{mL}$ antiBDNF or $0.2 \mu \mathrm{g} / \mathrm{mL}$ anti-NT-3 antibody. G: Immunocytochemistry performed on DRG using antineurofilament. F: Quantification of neurite outgrowth in DRG incubated with CM from M(CSF1 + DMS0), M(CSF-1 + E2), or M(CSF-1 + E2) in combination with anti-BDNF or anti-NT-3. Statistical analysis was performed using a one-way analysis of variance and Newman Keuls post test. ${ }^{*} P<0.01,{ }^{*} * P<0.001 . n=5$ volunteers $(\mathbf{E}$ and $\mathbf{F})$. Scale bar $=500 \mu \mathrm{m}(\mathbf{B}, \mathbf{C}$, and $\mathbf{G})$. DRG media, unconditioned DRG growth media; Mac media, unconditioned macrophage growth media; $R Q$, relative quantification.
$\mathrm{M}(\mathrm{CSF}-1+\mathrm{E} 2)$. All isolated cells were confirmed as macrophages using CD68 immunocytochemistry (Figure 1M). $\mathrm{M}(\mathrm{CSF}-1+\mathrm{E} 2)$ contained mRNAs encoding ER $\alpha$ and ER $\beta$ (Supplemental Figure S3, A and B). Protein localization revealed a mixed population of ER $\alpha$-positive and $E R \alpha$-negative macrophages; ER $\alpha$ was detected in $66 \%$ of cells (Figure $1 \mathrm{~N}$ ), whereas ER $\beta$ was detected in all cells (Figure 10).

\section{Nerve Fibers Recruit Macrophages in an E2-Dependent Manner in Vitro}

We explored the impact of products secreted by DRGs in response to stimulation with $\mathrm{E} 2$ on the migration of $\mathrm{M}(\mathrm{CSF}-1)$ using an in vitro macrophage migration assay. CM from DRGs stimulated for 24 hours with DMSO, E2, or E2 plus the anti-estrogen ICI were placed in one chamber, and $\mathrm{M}(\mathrm{CSF}-1)$ were placed in the other chamber (Figure 2A). M(CSF-1) migrated furthest toward CM from
DRG exposed to E2 $(P<0.01)$; this effect was not observed using CM from DRG exposed to E2 + ICI, indicating an ER-specific effect (Figure 2B). Notably, the addition of $\mathrm{E} 2$ to the medium in the absence of DRG had no effect on the migration of the macrophages (data not shown), verifying a role for E2-dependent DRG-derived secretory products in enhancing macrophage migration. qPCR analysis of E2-treated DRGs revealed ER-dependent regulation of a macrophage growth factor and two chemokines. Specifically, mRNA concentrations of Csf-1 were up-regulated by E2 $(P<0.001)$ (Figure $2 \mathrm{C})$, as were Ccl-2 and Ccl-3 mRNAs $(P<0.05)$ (Figure 2, D and $E)$. The addition of ICI abrogated the effect of E2. The addition of an anti-CCL-2 antibody to DRG CM abolished the E2-induced macrophage chemotactic properties $(P<0.01)$, whereas the addition of an anti-CCL-3 antibody attenuated E2-induced macrophage chemotactic properties of DRG CM (Figure 2F). 
A
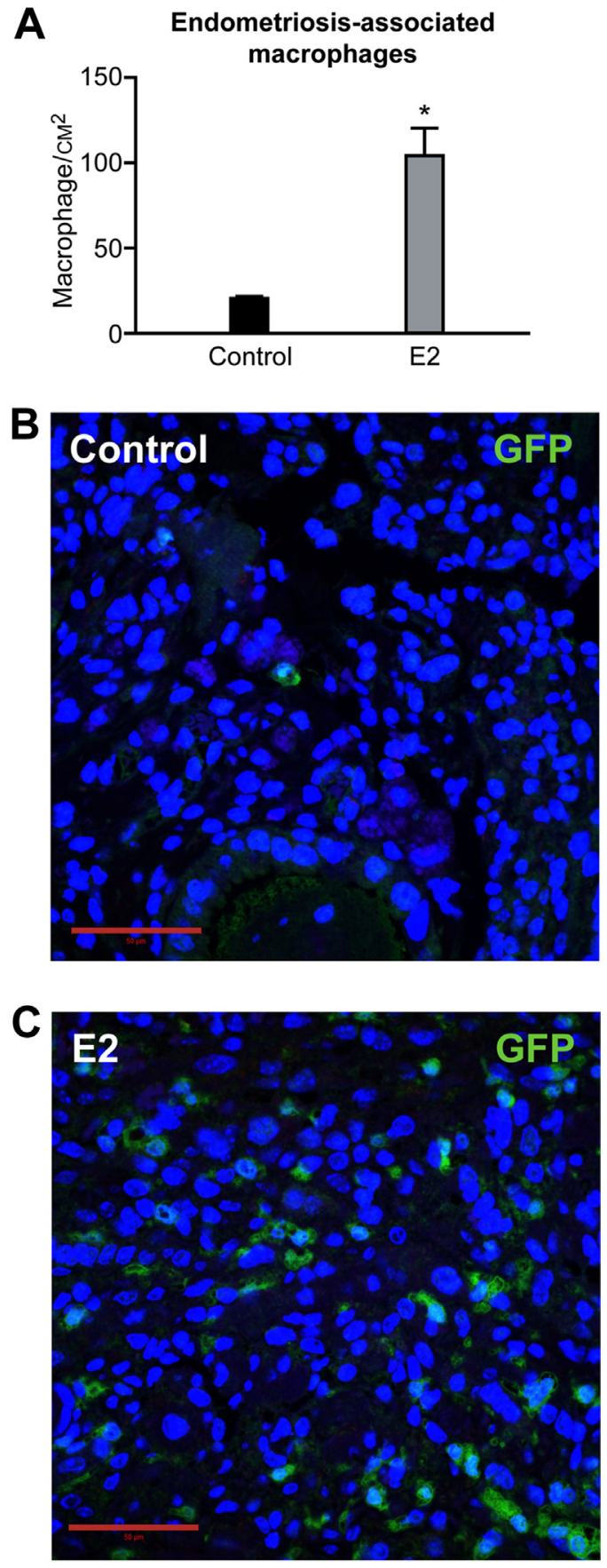

D

\section{Ccl-3}

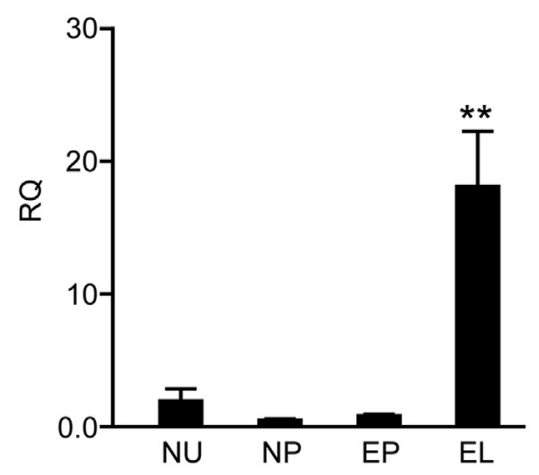

\section{E2 Induces Neurotrophic Properties in Macrophages}

DRGs were cultured in CM from M(CSF-1), and neurite outgrowth was recorded (Figure 3A). CM from E2activated macrophages $\mathrm{M}(\mathrm{CSF}-1+\mathrm{E} 2)$ significantly enhanced neurite outgrowth compared with $\mathrm{CM}$ from $\mathrm{M}(\mathrm{CSF}-1+\mathrm{DMSO})$ or M(CSF-1 + E2 + ICI) at 24 and 48 hours $(P<0.001)$ (Figure 3, B-D). Analysis of M(CSF-1) mRNAs revealed that NTs were up-regulated by E2 treatment. Specifically, mRNA concentrations of BDNF and NT-3 were significantly increased in M(CSF$1+$ E2) compared with M(CSF-1 + DMSO $)(P<0.001$ and $P<0.01$, respectively) (Figure 3, E and F). This effect was abrogated by the addition of ICI, confirming it was receptor dependent. To verify a role for BDNF and NT-3 in the neurotrophic properties of M(CSF-1 + E2), single whole DRGs were incubated with $\mathrm{CM}$ from $\mathrm{M}(\mathrm{CSF}-1)$ (Figure 3A) in combination with neutralizing antibodies targeted to BDNF or NT-3. The neurotrophic properties of $\mathrm{CM}$ from $\mathrm{M}(\mathrm{CSF}-1+\mathrm{E} 2)$ were abolished by anti-BDNF or anti-NT-3 $(P<0.01)$ (Figure $3, \mathrm{G}$ and $\mathrm{H}$ ). This effect was not observed when the neutralizing antibodies were added to DRG cultured in neuronal media in the presence of NGF.

\section{Macrophage Infiltration of Endometriosis Lesions Is E2 Dependent in a Mouse Model of Endometriosis}

Lesions recovered from mice exposed to E2 contained significantly more $\mathrm{GFP}^{+}$cells than mice that had hormonal support withdrawn $(P<0.05)$ (Figure $4, \mathrm{~A}-\mathrm{C})$. We have previously reported that $\mathrm{Ccl}-2$ and $\mathrm{Ccl}-5$ (regulated on activation normal T-cell expressed and secreted) mRNA concentrations were elevated in mouse endometriosis lesions, ${ }^{9}$ and herein we show that mRNA concentrations of the chemokine Ccl-3 were also significantly elevated in mouse endometriosis lesions $(P<0.01)$ compared with biopsy specimens of naïve uterus and peritoneum (Figure 4D).

Figure 4 Macrophage infiltration of lesions is estradiol (E2) dependent in a mouse model of endometriosis. A: Exposure of endometriosis mice to E2 increases the number of macrophages present in endometriosis lesions compared with lesions from mice that had E2 support withdrawn 7 days earlier (control). The numbers of macrophages per lesion were counted and normalized to lesion area. B and C: Images show representative fields of view from control mice (B) or mice exposed to E2 (C). Immunofluorescence was performed using an anti-green fluorescent protein (GFP) antibody (green), and nuclei are stained blue with DAPI. D: Quantitative PCR analysis reveals that $\mathrm{C}-\mathrm{C}$ motif ligand $(\mathrm{CCl})-3$ mRNA concentrations are elevated in lesions recovered from a mouse model of endometriosis. mRNA concentrations were measured in the uterus and peritoneum of naïve mice ( $N U$ and NP, respectively) and the peritoneum (EP) and lesions (EL) of mice with endometriosis. Statistical analysis was performed using a Student's unpaired $t$-test or a one-way analysis of variance and Newman Keuls post test. ${ }^{*} P<0.05,{ }^{*} P<0.01 . n=6$ (A, E2 group); $n=4$ (A, control group); $n=6$ (D, NU and NP groups); $n=8$ (D, EP and EL groups). Scale bar $=50 \mu \mathrm{m}(\mathbf{B}$ and $\mathbf{C}) . R Q$, relative quantification. 
A

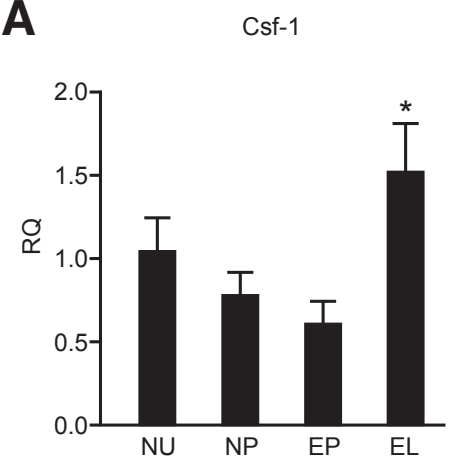

D

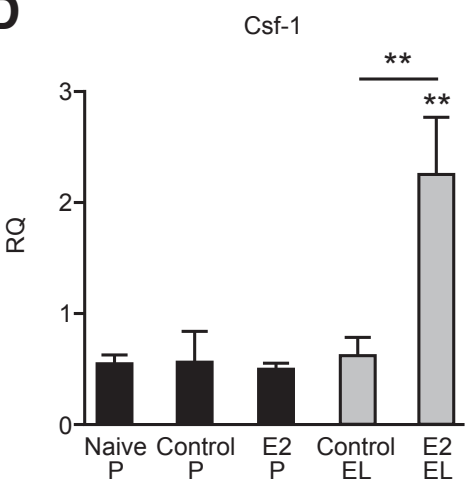

B

Nt-3
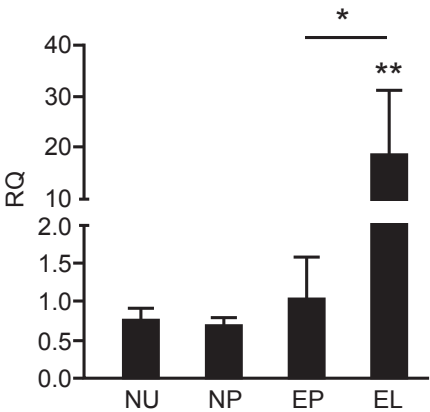

$\mathbf{E}$

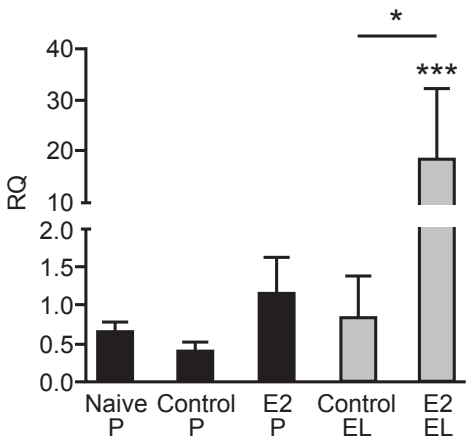

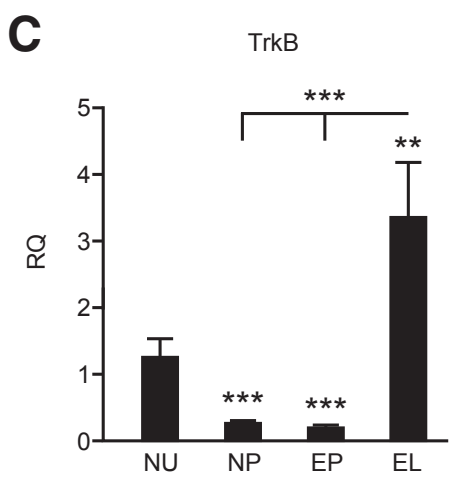

$\mathbf{F}$

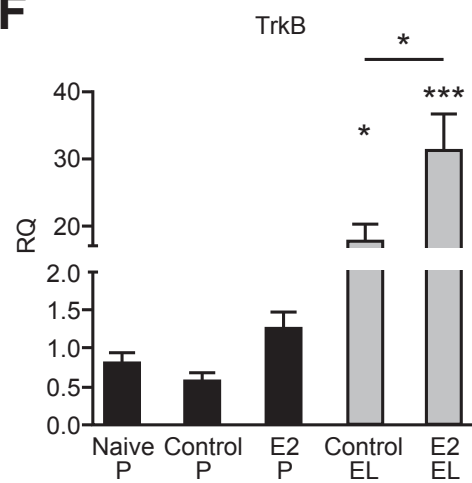

Figure 5 Colony-stimulating factor (Csf)-1, neurotrophin (Nt)-3, and tyrosine kinase receptor that binds both Bdnf and Nt-3 (TrkB) mRNA concentrations are elevated in endometriosis lesions and estradiol (E2) regulated in a mouse model of endometriosis. A-C: Csf-1, Nt-3, and TrkB are elevated in lesions recovered from a mouse model of endometriosis. mRNA concentrations of Csf-1 (A), Nt-3 (B), and TrkB (C) were measured in the uterus and peritoneum of naïve mice (NU and NP, respectively) and the peritoneum (EP) and lesions (EL) of mice with endometriosis. D-F: Csf-1, Nt-3, and TrkB are regulated by E2 in mouse endometriosis lesions. In a separate experiment, mice were separated into groups that continued exposure to E2 (E2) or had estradiol treatment withdrawn (control) for an additional 7 days. Peritoneal (P) and lesion (EL) biopsy specimens were included in the analysis. Peritoneum from naïve mice (naïve P) was also included. mRNA concentrations of Csf-1 (D), Nt-3 (E), and TrkB (F) are elevated in lesions from mice exposed to E2 compared with control mice. Statistical analysis was performed using a one-way analysis of variance and a Newman Keuls post test. ${ }^{*} P<0.05, * * P<0.01$, and ${ }^{* * *} P<0.001 . n=6$ (A-C, NU and NP groups); $n=8$ (A-C, EP and EL groups); $n=6$ (D-F, E2 and naïve P groups); $n=5$ (D-F, control). RQ, relative quantification.

\section{Csf-1, Nt-3, and TrkB Are E2 Regulated in a Mouse Model of Endometriosis}

Csf-1 and Nt-3 mRNA concentrations were significantly higher in lesions than other tissue samples (Figure 5, A and B). mRNA concentrations of the tyrosine kinase receptor that binds both Bdnf and Nt-3 (TrkB) were also up-regulated in lesions (Figure 5C). Concentrations of mRNAs encoded by Csf1, Nt3, and Ntrk2 were significantly higher in the lesions exposed to E2 compared with those recovered from mice in which E2 was withdrawn after lesions were established (Figure 5, D-F).

\section{Discussion}

Endometriosis is a steroid-dependent disorder; lesions exhibit the capacity for enhanced tissue biosynthesis of estrogens and alterations in ER protein expression. ${ }^{21,23}$ Herein, we provide new evidence that estrogens play a key role in the regulation of interactions between macrophages and nerve fibers in endometriosis. Specifically, by using in vitro model systems, we found that DRG neurons produced chemokines in response to
E2 that promoted macrophage recruitment, whereas macrophages stimulated with E2 produced NTs that promoted neuronal outgrowths. By using a mouse model of endometriosis, ${ }^{9}$ we demonstrated that macrophage infiltration of endometriosis lesions was E2 dependent and that the concentrations of mRNAs encoding Csf-1, Nt-3, and TrkB were E2 regulated in mouse lesions.

\section{ER Expression by Endometriosis-Associated Macrophages Suggests a Heterogeneous Population}

Estrogen can bind directly to either $\mathrm{ER} \alpha$ or $\mathrm{ER} \beta$, resulting in ligand-dependent changes in receptor function and gene expression. We have previously demonstrated that endothelial cells within both normal endometrium ${ }^{14,24}$ and peritoneal lesions $^{21}$ are $\mathrm{ER} \beta^{+} / \mathrm{ER} \alpha^{-}$. Notably, E2 treatment of immortalized human endometrial endothelial cells resulted in changes in gene expression of the axonal guidance factor SLIT3, consistent with the suggestion that neuroangiogenesis can be modulated by estrogen.

In this study, we used fluorescent immunohistochemistry to explore the ER phenotype of macrophages within eutopic 


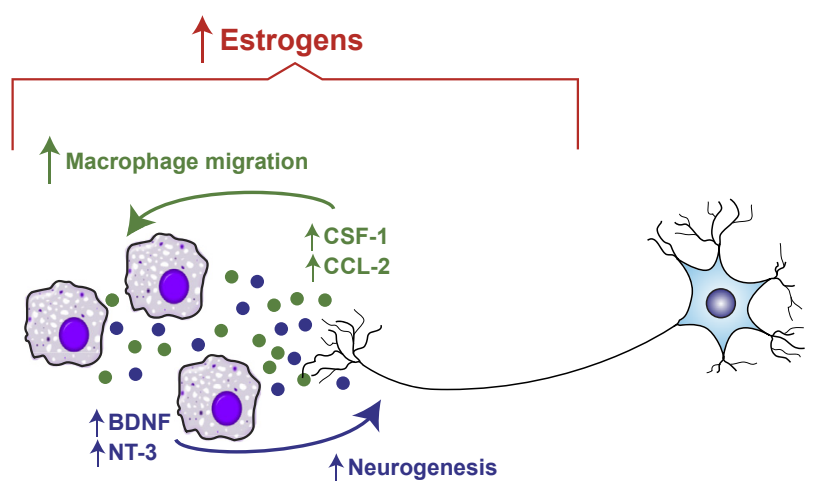

Figure 6 Estradiol enhances the interactions between macrophages and nerve fibers in endometriosis. Schematic representation of macrophage-nerve interactions in endometriosis. Nerve fibers increase the production of colony-stimulating factor (CSF)- 1 and C-C motif ligand (CCL)-2 in response to estradiol, which enhances macrophage migration. Estradiol also acts on macrophages to increase production of brainderived neurotrophic factor (BDNF) and neurotrophin (NT)-3, resulting in increased neurogenesis.

and ectopic endometrium in women and in a mouse model. Notably, all $\mathrm{CD}^{+} 8^{+}$macrophages in the peritoneum and lesions from women, and all $\mathrm{GFP}^{+}$macrophages in the peritoneum and lesions from mice, were immunopositive for ER $\beta$. In contrast, peritoneal and lesion resident macrophages were a mixed population of $\mathrm{ER} \alpha^{+}$and $\mathrm{ER} \alpha^{-}$cells. There was no clear evidence of either population residing in specific microenvironments, because $\mathrm{ER} \alpha^{+}$cells were often detected adjacent to $\mathrm{ER} \alpha^{-}$cells.

As we have previously reported data from our mouse model of endometriosis showing that the lesion-resident $\mathrm{GFP}^{+}$macrophages may originate from both the peritoneum and the shed endometrium, ${ }^{9}$ we wondered if the heterogeneous expression of ER $\alpha$ might be a reflection of different origins (endometrial macrophages are all $\mathrm{ER} \alpha^{-}$), However, because there was no significant difference in proportions of $\mathrm{ER} \alpha^{+}$cells in lesions and peritoneum, this cannot be the case. It, therefore, remains to be determined what regulates the amount of $\mathrm{ER} \alpha$ protein in $\mathrm{CD} 68^{+}$macrophages. One plausible explanation is that the ER $\alpha$ cells have infiltrated from peripheral blood ( $E R \alpha$ is expressed by peripheral blood monocyte-derived macrophages).

Macrophages isolated from the peritoneal fluid of women with endometriosis are reported to be immunopositive for both $\mathrm{ER} \alpha$ and ER $\beta$, and ER immunolocalization increases in women with endometriosis compared with women without endometriosis. ${ }^{16,25}$ ER expression in lesion-resident macrophages had not been examined until now. Our findings differed from the previous studies in that $\mathrm{ER} \alpha$ was only detected in a subset of macrophages in both peritoneal (from women without endometriosis) and lesion biopsy specimens ${ }^{16,25}$; we also found no difference in ER immunolocalization in macrophages from women with and without endometriosis. We suggest that this discrepancy in findings is because of the inherent differences between peritoneal fluid macrophages (naïve and un-stimulated in disease-free conditions) ${ }^{26}$ and tissue macrophages (activated). Although the phenotype of macrophages present in the eutopic endometrium may alter throughout the menstrual cycle, ${ }^{27}$ recent reports suggest that they have a phenotype closer to the alternative (M2-like) end of the macrophage activation spectrum $^{28}$; a similar phenotype has been reported for endometriosis-associated macrophages. ${ }^{7}$ We postulate that macrophages in the shed endometrium may retain their phenotype, and the local endometrial microenvironment of the ectopic endometrial tissue reprograms the macrophages infiltrating the lesion from the peritoneum.

\section{E2 Mediates a Two-Way Dialogue between Macrophages and Nerves}

We and others documented the presence of macrophages and nerves in close association in tissue sections from lesions. ${ }^{6}$ The nuclei of sensory neurons innervating the uterus are known to express ERs, ${ }^{15}$ and ER-dependent signaling modulates a range of processes in peripheral nerves. ${ }^{29,30} \mathrm{We}$ were, therefore, interested in exploring whether the estrogen-dominated microenvironment could play a role in modulating interactions between macrophages and nerves and what regulatory factors may be involved. By using a migration assay to determine whether neurons could release factors influencing macrophages, we found evidence that addition of CM from DRGs treated with E2 enhanced macrophage migration and that the mRNA concentrations of Ccl-2 and Ccl-3 in DRGs was ER regulated. More important, when an antibody directed against Ccl-2 was added to the $\mathrm{CM}$, macrophage migration was abrogated, implicating a key E2-dependent factor involved in neuron-mediated macrophage migration. Notably, elevated CCL-2 concentrations have been detected in peritoneal fluid of women with endometriosis. ${ }^{31}$ Moreover, Luk et al ${ }^{32}$ demonstrated that CCL-2 concentrations are increased by E2 in endometrial endothelial cells from women with endometriosis. Their study and ours both provide evidence that E2 modulates recruitment of macrophages via CCL-2 to endothelial cells and nerve fibers in endometriosis lesions.

CSF-1 is a critical growth factor involved in macrophage survival, proliferation, and differentiation. ${ }^{33} \mathrm{Csf}-1$ may play a critical role in early development of endometriosis lesions; mice homozygous for a Csfl mutation (Csf-1 op/op) developed significantly fewer lesions in a model of endometriosis compared with wild-type controls. ${ }^{34}$ Elevated CSF-1 concentrations have also been reported in the peritoneal fluid of women with endometriosis. ${ }^{35}$ In our study, mRNA concentrations of $C s f-1$ were increased in lesions recovered from mice and were also increased in DRGs exposed to E2. On the basis of these results, we suggest that the ER-dependent regulation of CSF-1 in peripheral nerve fibers present in endometriosis lesions may play a role in modulating macrophage survival and phenotype, and is consistent with the hypothesis that neurogenic inflammation is a key process in this disorder. 
E2 is reported to be neuroprotective ${ }^{36}$; these effects have been linked to E2-dependent expression of BDNF, promoting neuron survival, regeneration, and synaptogenesis. ${ }^{37}$ NT-3 is elevated in the peritoneal fluid of women with endometriosis, ${ }^{38}$ but the cellular source is uncertain. In this study, E2 increased the neurotrophic properties of macrophages via up-regulation of BDNF and NT3, suggesting that this cell type is a key source of these NTs contributing to E2-dependent nerve growth into lesions. Notably, the mRNA concentrations of Nt-3 and the NT receptor TrkB were also E2 regulated in the lesions induced in mice, complementing the data from the in vitro models.

\section{Endometriosis Is a Neuroinflammatory Disorder}

It has been proposed that endometriosis-associated macrophages may identify the ectopic endometrial tissue as a wound and activate pathways supporting cell survival and angiogenesis, rather than phagocytosis of ectopic material. ${ }^{39}$ Macrophages are vital in the regeneration of damaged nerves after injury to the central nervous system and peripheral nervous system and, although infiltrating sensory nerves present within endometriosis lesions are not damaged per se, they may experience a chemical milieu similar to inflammation in response to trauma ${ }^{40}$ In a mouse model of acute peripheral nerve injury, an alternative macrophage response was detected, ${ }^{41}$ and this phenotype has been associated with a sterile inflammatory environment similar to endometriosis. We suggest that the reciprocal relationship between macrophages and nerves encourages innervation of endometriosis lesions. Moreover, the close proximity of macrophages and nerves within lesions suggests that macrophage-derived cytokines may also contribute to pelvic pain in endometriosis by acting directly on nociceptors generating a pain response and hypersensitivity. ${ }^{40,42}$ We have previously shown that estrogens can also act directly on human sensory neurons to increase the mRNA concentrations of key nociceptive ion channels, including TAC1, P2RX3, and TRPV1, ${ }^{43}$ further supporting a role for estrogens in modulating pain response in endometriosis by acting on nerves.

Our data have led us to propose the following model: elevated levels of estrogens present within the lesion microenvironment act to mediate interactions between macrophages and nerve fibers, whereby estrogen acts on nerve fibers to enhance the expression of CSF1 and CCL-2, recruiting macrophages to nerve fibers. Reciprocally, estrogens act on macrophages to enhance expression of BDNF and NT-3, which further potentiates neurogenesis into lesions (Figure 6). In conclusion, these new results provide compelling evidence that estrogens produced by the ovaries, as well as within lesions, play a pivotal role in cross talk between neurons and macrophages, which underpins development of pain symptoms in women with endometriosis. The identification of E2-dependent factors that regulate the process of macrophage-mediated nerve growth into lesions may offer novel targets for inhibition that may be preferred over medically induced hypoestrogenism.

\section{Acknowledgments}

We thank all of the women who gave informed consent for the use of their material in this study; our research nurses Ann Doust and Helen Dewart, who organized the tissue collection; Ronnie Grant for preparation of figures; Prof. Adriano Rossi for critical feedback on experiments and the manuscript; Dr. Uma Thiruchelvam for initial advice on macrophage phenotype and isolation; and Dr. Maria Luisa Barcena de Arellano for her input.

E.G. conceived and performed experiments and analyzed data, J.T. performed experiments and analyzed data, A.E.-Z. performed experiments, S.M. and A.W.H. collected patient biopsy specimens, P.T.K.S. conceived experiments, and E.G., A.W.H., and P.T.K.S. wrote the manuscript.

\section{Supplemental Data}

Supplemental material for this article can be found at http://dx.doi.org/10.1016/j.ajpath.2015.04.012.

\section{References}

1. Giudice LC, Kao LC: Endometriosis. Lancet 2004, 364:1789-1799

2. Barcena de Arellano ML, Mechsner S: The peritoneum: an important factor for pathogenesis and pain generation in endometriosis. J Mol Med (Berl) 2014, 92:595-602

3. Cao X, Yang D, Song M, Murphy A, Parthasarathy S: The presence of endometrial cells in the peritoneal cavity enhances monocyte recruitment and induces inflammatory cytokines in mice: implications for endometriosis. Fertil Steril 2004, 82(Suppl 3):999-1007

4. Burney RO, Giudice LC: Pathogenesis and pathophysiology of endometriosis. Fertil Steril 2012, 98:511-519

5. Asante A, Taylor RN: Endometriosis: the role of neuroangiogenesis Annu Rev Physiol 2011, 73:163-182

6. Tran LV, Tokushige N, Berbic M, Markham R, Fraser IS: Macrophages and nerve fibres in peritoneal endometriosis. Hum Reprod 2009, 24:835-841

7. Bacci M, Capobianco A, Monno A, Cottone L, Di Puppo F, Camisa B, Mariani M, Brignole C, Ponzoni M, Ferrari S, Panina-Bordignon P, Manfredi AA, Rovere-Querini P: Macrophages are alternatively activated in patients with endometriosis and required for growth and vascularization of lesions in a mouse model of disease. Am J Pathol 2009, 175:547-556

8. Capobianco A, Monno A, Cottone L, Venneri MA, Biziato D, Di Puppo F, Ferrari S, De Palma M, Manfredi AA, Rovere-Querini P: Proangiogenic Tie2(+) macrophages infiltrate human and murine endometriotic lesions and dictate their growth in a mouse model of the disease. Am J Pathol 2011, 179:2651-2659

9. Greaves E, Cousins FL, Murray A, Esnal-Zufiaurre A, Fassbender A, Horne AW, Saunders PT: A novel mouse model of endometriosis mimics human phenotype and reveals insights into the inflammatory contribution of shed endometrium. Am J Pathol 2014, 184:1930-1939

10. Arnold J, Barcena de Arellano ML, Ruster C, Vercellino GF, Chiantera V, Schneider A, Mechsner S: Imbalance between sympathetic and sensory innervation in peritoneal endometriosis. Brain Behav Immun 2012, 26:132-141

11. Tokushige N, Markham R, Russell P, Fraser IS: Nerve fibres in peritoneal endometriosis. Hum Reprod 2006, 21:3001-3007

12. Rosenberg AF, Wolman MA, Franzini-Armstrong C, Granato M: In vivo nerve-macrophage interactions following peripheral nerve injury. J Neurosci 2012, 32:3898-3909 
13. Fang Z, Yang S, Gurates B, Tamura M, Simpson E, Evans D, Bulun SE: Genetic or enzymatic disruption of aromatase inhibits the growth of ectopic uterine tissue. J Clin Endocrinol Metab 2002, 87: 3460-3466

14. Critchley HO, Henderson TA, Kelly RW, Scobie GS, Evans LR, Groome NP, Saunders PT: Wild-type estrogen receptor (ERbeta1) and the splice variant (ERbetacx/beta2) are both expressed within the human endometrium throughout the normal menstrual cycle. J Clin Endocrinol Metab 2002, 87:5265-5273

15. Papka RE, Storey-Workley M, Shughrue PJ, Merchenthaler I, Collins JJ, Usip S, Saunders PT, Shupnik M: Estrogen receptor-alpha and beta- immunoreactivity and mRNA in neurons of sensory and autonomic ganglia and spinal cord. Cell Tissue Res 2001, 304: $193-214$

16. Capellino S, Montagna P, Villaggio B, Sulli A, Soldano S, Ferrero S, Remorgida V, Cutolo M: Role of estrogens in inflammatory response: expression of estrogen receptors in peritoneal fluid macrophages from endometriosis. Ann N Y Acad Sci 2006, 1069:263-267

17. Khan KN, Masuzaki H, Fujishita A, Kitajima M, Sekine I, Matsuyama T, Ishimaru T: Estrogen and progesterone receptor expression in macrophages and regulation of hepatocyte growth factor by ovarian steroids in women with endometriosis. Hum Reprod 2005, 20:2004-2013

18. Noyes RW, Haman JO: Accuracy of endometrial dating: correlation of endometrial dating with basal body temperature and menses. Fertil Steril 1953, 4:504-517

19. Sasmono RT, Oceandy D, Pollard JW, Tong W, Pavli P, Wainwright BJ, Ostrowski MC, Himes SR, Hume DA: A macrophage colony-stimulating factor receptor-green fluorescent protein transgene is expressed throughout the mononuclear phagocyte system of the mouse. Blood 2003, 101:1155-1163

20. Cousins FL, Murray A, Esnal A, Gibson DA, Critchley HO, Saunders PT: Evidence from a mouse model that epithelial cell migration and mesenchymal-epithelial transition contribute to rapid restoration of uterine tissue integrity during menstruation. PLoS One 2014, 9:e86378

21. Greaves E, Collins F, Esnal-Zufiaurre A, Giakoumelou S, Horne AW, Saunders PT: Estrogen receptor (ER) agonists differentially regulate neuroangiogenesis in peritoneal endometriosis via the repellent factor SLIT3. Endocrinology 2014, 155:4015-4026

22. Murray PJ, Allen JE, Biswas SK, Fisher EA, Gilroy DW, Goerdt S, Gordon S, Hamilton JA, Ivashkiv LB, Lawrence T, Locati M, Mantovani A, Martinez FO, Mege JL, Mosser DM, Natoli G, Saeij JP, Schultze JL, Shirey KA, Sica A, Suttles J, Udalova I, van Ginderachter JA, Vogel SN, Wynn TA: Macrophage activation and polarization: nomenclature and experimental guidelines. Immunity 2014, 41:14-20

23. Bulun SE, Gurates B, Fang Z, Tamura M, Sebastian S, Zhou J, Amin S, Yang S: Mechanisms of excessive estrogen formation in endometriosis. J Reprod Immunol 2002, 55:21-33

24. Greaves E, Collins F, Critchley HO, Saunders PT: ERbeta-dependent effects on uterine endothelial cells are cell specific and mediated via Sp1. Hum Reprod 2013, 28:2490-2501

25. Montagna P, Capellino S, Villaggio B, Remorgida V, Ragni N, Cutolo M, Ferrero S: Peritoneal fluid macrophages in endometriosis: correlation between the expression of estrogen receptors and inflammation. Fertil Steril 2008, 90:156-164
26. Zhang X, Goncalves R, Mosser DM: The isolation and characterization of murine macrophages. Curr Protoc Immunol 2008, Chapter 14:Unit 14.1

27. Thiruchelvam U, Dransfield I, Saunders PT, Critchley HO: The importance of the macrophage within the human endometrium. J Leukoc Biol 2013, 93:217-225

28. Cominelli A, Gaide Chevronnay HP, Lemoine P, Courtoy PJ, Marbaix E, Henriet P: Matrix metalloproteinase-27 is expressed in CD163+/CD206+ M2 macrophages in the cycling human endometrium and in superficial endometriotic lesions. Mol Hum Reprod 2014, 20:767-775

29. Rowan MP, Berg KA, Roberts JL, Hargreaves KM, Clarke WP: Activation of estrogen receptor alpha enhances bradykinin signaling in peripheral sensory neurons of female rats. J Pharmacol Exp Ther 2014, 349:526-532

30. Xu S, Cheng Y, Keast JR, Osborne PB: 17beta-Estradiol activates estrogen receptor beta-signalling and inhibits transient receptor potential vanilloid receptor 1 activation by capsaicin in adult rat nociceptor neurons. Endocrinology 2008, 149:5540-5548

31. Bersinger NA, Dechaud H, McKinnon B, Mueller MD: Analysis of cytokines in the peritoneal fluid of endometriosis patients as a function of the menstrual cycle stage using the Bio-Plex(R) platform. Arch Physiol Biochem 2012, 118:210-218

32. Luk J, Seval Y, Ulukus M, Ulukus EC, Arici A, Kayisli UA: Regulation of monocyte chemotactic protein-1 expression in human endometrial endothelial cells by sex steroids: a potential mechanism for leukocyte recruitment in endometriosis. Reprod Sci 2010, 17:278-287

33. Wynn TA, Chawla A, Pollard JW: Macrophage biology in development, homeostasis and disease. Nature 2013, 496:445-455

34. Jensen JR, Witz CA, Schenken RS, Tekmal RR: A potential role for colony-stimulating factor 1 in the genesis of the early endometriotic lesion. Fertil Steril 2010, 93:251-256

35. Fukaya T, Sugawara J, Yoshida H, Yajima A: The role of macrophage colony stimulating factor in the peritoneal fluid in infertile patients with endometriosis. Tohoku J Exp Med 1994, 172:221-226

36. Baudry M, Bi X, Aguirre C: Progesterone-estrogen interactions in synaptic plasticity and neuroprotection. Neuroscience 2013, 239: 280-294

37. Sohrabji F, Lewis DK: Estrogen-BDNF interactions: implications for neurodegenerative diseases. Front Neuroendocrinol 2006, 27:404-414

38. Barcena de Arellano ML, Arnold J, Lang H, Vercellino GF, Chiantera V, Schneider A, Mechsner S: Evidence of neurotrophic events due to peritoneal endometriotic lesions. Cytokine 2013, 62: 253-261

39. Capobianco A, Rovere-Querini P: Endometriosis, a disease of the macrophage. Front Immunol 2013, 4:9

40. Basbaum AI, Bautista DM, Scherrer G, Julius D: Cellular and molecular mechanisms of pain. Cell 2009, 139:267-284

41. Ydens E, Cauwels A, Asselbergh B, Goethals S, Peeraer L, Lornet G, Almeida-Souza L, Van Ginderachter JA, Timmerman V, Janssens S: Acute injury in the peripheral nervous system triggers an alternative macrophage response. J Neuroinflammation 2012, 9:176

42. Sommer C, Kress M: Recent findings on how proinflammatory cytokines cause pain: peripheral mechanisms in inflammatory and neuropathic hyperalgesia. Neurosci Lett 2004, 361:184-187

43. Greaves E, Grieve K, Horne AW, Saunders PT: Elevated peritoneal expression and estrogen regulation of nociceptive ion channels in endometriosis. J Clin Endocrinol Metab 2014, 99:E1738-E1748 